\title{
Dietary supplement consumption among cardiac patients admitted to internal medicine and cardiac wards
}

\author{
Orith Karny-Rahkovich ${ }^{1 *}$, Alex Blatt ${ }^{2 *}$, Gabby Atalya Elbaz-Greener ${ }^{2}$,
} Tomer Ziv-Baran ${ }^{3}$, Ahuva Golik ${ }^{4}$, Matityahu Berkovitch ${ }^{5}$

\begin{abstract}
${ }^{1}$ Internal Medicine B, Assaf Harofeh Medical Center, Zerifin, affiliated to the Sackler School of Medicine, Tel-Aviv University, Israel; ${ }^{2}$ Cardiology Division, Assaf Harofeh Medical Center, Zerifin, affiliated to the Sackler School of Medicine, Tel-Aviv University, Israel; ${ }^{3}$ Department of Epidemiology and Preventive Medicine, School of Public Health, Sackler Faculty of Medicine, Tel Aviv University, Israel; ${ }^{4}$ Internal Medicine A, Assaf Harofeh Medical Center, Zerifin, affiliated to the Sackler School of Medicine, Tel-Aviv University, Israel; ${ }^{5}$ The Clinical Pharmacology and Toxicology Unit, Assaf Harofeh Medical Center, Zerifin, affiliated to the Sackler School of Medicine, Tel-Aviv University, Israel
\end{abstract}

\section{Abstract}

Background: Dietary supplements may have adverse effects and potentially interact with conventional medications. They are perceived as "natural" products, free of side effects with no need for medical consultation. Little is known about consumption of dietary supplements by patients with cardiac diseases. The objective of this study was to investigate dietary supplement consumption among cardiac patients admitted to internal and cardiology wards. Potential drug-dietary supplement interactions were also assessed.

Methods: During a period of 6 months, patients with cardiac disease hospitalized in the Internal Medicine and Cardiology Wards at Assaf Harofeh Medical Center were evaluated regarding their dietary supplement consumption. A literature survey examining possible drug-supplement interaction was performed.

Results: Out of 149 cardiac patients, $45 \%$ were dietary supplement consumers. Patients admitted to the Internal Medicine Wards consumed more dietary supplements than those admitted to the Cardiology Division. Dietary supplement consumption was associated with older age $(O R=1.05, p=0.022)$, female gender $(O R=2.94, p=0.014)$ and routine physical activity $(O R=3.15, p=0.007)$. Diabetes mellitus $(O R=2.68, p=0.020)$, hematological diseases $(O R=13.29, p=0.022)$, and the use of anti-diabetic medications $(O R=4.28, p=0.001)$ were independently associated with dietary supplement intake. Sixteen potential moderate interactions between prescribed medications and dietary supplements were found.

Conclusions: Consumption of dietary supplements is common among cardiac patients. It is more common in those admitted to Internal Medicine Departments than in those admitted to the Cardiology Wards. Due to the risk of various drug-supplement interactions consumed by patients with cardiac diseases, there is a need to increase awareness and knowledge among medical staff regarding the intake of dietary supplements. (Cardiol J 2015; 22, 5: 510-518)

Key words: cardiac patients, dietary supplements, drug-dietary supplements interactions

\section{Editorial p. 485}

Address for correspondence: Orith Karny-Rahkovich, MD, Internal Medicine B, Assaf Harofeh Medical Center, 70300, Zerifin, Israel, affiliated to the Sackler School of Medicine, Tel-Aviv University, Israel, tel: 97289779263, fax: 97289779266, e-mail: orithkr@gmail.com

*The first two authors equally contributed to the study.

Received: 18.03.2015 Accepted: 25.05.2015 


\section{Introduction}

The use of dietary supplements/vitamins/ /medicinal plants (hereinafter: dietary supplements) has increased consistently over the last few years. In the United States, 1 in 4 persons consuming prescription medications takes also dietary supplements [1]. According to the Dietary Supplement Health and Education Act (DSHEA), the definition of a dietary supplement is: "a product that is intended to supplement the diet, contains one or more dietary ingredients (including vitamins, minerals, herbs or other botanicals, amino acids, and certain other substances) or their constituents, is intended to be taken by mouth, in forms such as tablets, capsules, powders, softgels, gelcaps, or liquids, and are labeled as being a dietary supplement" [2]. Dietary supplements have been authorized for use based on their proven pharmacological activity (in clinical studies) or according to ancient traditions and to the subjective sense of the user [1].

Dietary supplements can affect the absorption, metabolism, and disposition of other drugs [1]. Currently, there is no sufficient evidencebased literature regarding the safety and efficacy of dietary supplements and of the possible dietary supplement-drug interactions. The regulations of the pre-clinical and clinical studies regarding dietary supplements are not as stringent as those testing conventional drugs, thus resulting in an increased risk of adverse effects.

Chronically ill patients are at a greater risk of these interactions due to the higher amount of prescription medications taken. This is especially true in narrow therapeutic range medications such as in seizure disorders, cardiac arrhythmias or congestive heart failure. The addition of any substance could result in an unwanted outcome, thereby subjecting those patients to an increased risk of disease deterioration [3].

One of the most studied dietary supplements is omega 3. Most of the epidemiological and intervention research studies that have been conducted on single cells, animals and humans have shown the advantageous effects of omega 3 on cardiovascular disease, including: various types of coronary heart disease, myocardial infarction, stroke, acute heart failure [4]. The use of omega 3 is currently recommended by the American Heart Association [5], American College of Cardiology [6], and European Society of Cardiology [7] for reducing the risk of cardiovascular disease.

In a study conducted in Israel among 299 patients, Goldstein et al. [8] reported that $19.3 \%$ of patients hospitalized for acute ischemic heart disease (IHD) as their leading diagnosis, consumed herbal supplements, compared to $31.1 \%$ of patients who had a history of IHD.

To the best of our knowledge, no study has been conducted in Israel and scarce data is available worldwide on "dietary supplement" intake in patients who suffer from various cardiac diseases. Thus, the aims of the current study were: A) To examine the characteristics of cardiac disease patients who consume dietary supplements and the frequency of their usage, B) To compare dietary supplement consumption in patients admitted to the Cardiology Division (the Intensive Care Cardiac Unit and the regular Cardiac Ward) and patients admitted to the Internal Medicine Wards, C) To search for potential adverse drug-supplement interactions.

\section{Methods}

The study included patients hospitalized with acute or chronic cardiac disease in the Internal Medicine Wards and the Cardiology Division at Assaf Harofeh Medical Center. Cardiac disease was defined as at least one of the following categories: IHD, congestive heart failure, valvular heart disease or arrhythmias. Children under the age of 18 years; dementia or mechanical ventilated patients were excluded from the study. The study was authorized by the Institutional Helsinki Committee and patients signed an informed consent form.

For each patient, the primary investigator or a pharmacist completed a questionnaire regarding demographics, medical history, medications and dietary supplements consumed on a regular basis.

Patients admitted to the Internal and Cardiology Wards were compared.

A literature review (Stockley's Drug Interactions, Stockley's Herbal Medicines Interactions, http://naturaldatabase.therapeuticresearch.com/) was conducted to explore the possibility of drug-supplement interactions.

\section{Statistical analysis}

Frequency and percentage were used to describe categorical variables (hospitalization ward, gender, religion, place of birth, family status, education, salary, physical activity, smoking, alcohol consumption, drug use, chronic diseases and medications). Continuous variables (age and body mass index) were examined for normal distribution using the Kolmogorov-Smirnov test and averages and standard deviations were computed. Univari- 
ate analysis was used to examine the relationship between categorical variables and the consumption of dietary supplements (using the $\chi^{2}$ test) and continuous variables between taking dietary supplements vs. not taking dietary supplements (by Student's t-test). Multivariate analysis was conducted using the logistic regression analysis. Age, gender and variables that were associated with consumption of dietary supplements shown by the univariate analysis $(\mathrm{p}<0.1)$ were entered to the regression. The regression was conducted using the backward method while age and gender were included by the Enter method. A p $<0.05$ was defined as statistically significant. All statistical tests were 2-tailed. All analyses were performed with the SPSS 21.0 software.

\section{Results}

One hundred and forty-nine patients were enrolled. Patients' demographic characteristics, habits and medical history are presented in Table 1. Thirty-two point nine percent of patients were admitted in Internal Medicine Wards and $67.1 \%$ were hospitalized in the Cardiology Division. Most of the patients were Jewish, born in Israel or Eastern Europe, married with at least 12 years of education, and with average salaries or above average.

Dietary supplements were consumed by $45 \%$ $(\mathrm{n}=67)$ of the patients. The consumption was divided as follows: $12.1 \%(n=18)$ of all patients consumed a single dietary supplement, $15.4 \%(\mathrm{n}=23)$ 2 dietary supplements, $8.7 \%(\mathrm{n}=13) 3$ dietary supplements, $3.1 \%(\mathrm{n}=5) 4$ dietary supplements, $2.7 \%(\mathrm{n}=4) 5$ dietary supplements and $2.7 \%(\mathrm{n}=4)$ consumed 6 dietary supplements.

The frequency of dietary supplement consumed by the patients according to supplement type is presented in Table 2.

The demographic characteristics, habits and medical history of patients consuming dietary supplements compared to the non-consumers are presented in Table 3. Consumers differed from non-consumers in age, gender, physical activity and smoking habits. Forty-nine point three percent of consumers were female in comparison to $24.4 \%$ in the non-consumer group and $35.6 \%$ in the total population of the study, $49.3 \%$ of consumers were physically active compared to $30.5 \%$ in the non-consumer group and $38.9 \%$ in the total study population, and $53.7 \%$ of consumers were non-smokers compared to $30.5 \%$ in the non-consumer group and $43.6 \%$ in the total study population. Notably, half of the supplement consumers suffered from a chronic
Table 1. Demographic characteristics, habits and medical history of all the patients.

\begin{tabular}{|c|c|}
\hline Characteristic & $\begin{array}{l}\text { Mean } \pm S D \\
\quad \text { or } n(\%)\end{array}$ \\
\hline Age & $11.14 \pm 64.15$ \\
\hline Body mass index & $29.53 \pm 4.88$ \\
\hline Gender (females/males) & $53(35.6) / 96(64.4)$ \\
\hline $\begin{array}{l}\text { Hospitalization Ward (Internal } \\
\text { Medicine/Cardiology) }\end{array}$ & $49(32.9) / 100(67.1)$ \\
\hline Food supplements consumers & $67(45)$ \\
\hline Religion (Jewish/Arabic) & $133(89.3) / 16(10.7)$ \\
\hline \multicolumn{2}{|l|}{ Place of birth: } \\
\hline Israel & $56(37.6)$ \\
\hline Eastern Europe & $53(35.6)$ \\
\hline North Africa & $20(13.4)$ \\
\hline Other & $20(13.4)$ \\
\hline \multicolumn{2}{|l|}{ Family status: } \\
\hline Married & $110(73.8)$ \\
\hline Single & $2(1.3)$ \\
\hline Divorced & $25(16.8)$ \\
\hline Widowed & $12(8.1)$ \\
\hline \multicolumn{2}{|l|}{ Education: } \\
\hline No education & $9(6)$ \\
\hline Elementary school & $24(16.1)$ \\
\hline High school & $57(38.3)$ \\
\hline Academic & $59(39.6)$ \\
\hline \multicolumn{2}{|l|}{ Salary: } \\
\hline Significantly below average & $5(3.4)$ \\
\hline Below average & $20(13.4)$ \\
\hline Average & $24(16.1)$ \\
\hline Above average & $41(27.5)$ \\
\hline Significantly above average & $59(39.6)$ \\
\hline $\begin{array}{l}\text { Physical activity } \\
\text { (active/non-active) }\end{array}$ & $58(38.9) / 91(61.1)$ \\
\hline \multicolumn{2}{|l|}{ Smoking: } \\
\hline Non smoker & $65(43.6)$ \\
\hline Smoker & $34(22.8)$ \\
\hline Past smoker & $50(33.6)$ \\
\hline Routine alcohol consumption & $10(6.7)$ \\
\hline Drug use & $2(1.3)$ \\
\hline Acute ischemic heart disease & $69(46.3)$ \\
\hline Chronic ischemic heart disease & $73(49.0)$ \\
\hline Congestive heart failure & $33(22.1)$ \\
\hline Valvular heart disease & $12(8.1)$ \\
\hline Cardiac arrhythmia & 38 (25.5) \\
\hline
\end{tabular}

IHD (49.3\%) and/or diabetes mellitus (50.7\%). Multivariate and backward regression analysis revealed that dietary supplement consumption was associated with older age $(\mathrm{OR}=1.05, \mathrm{p}=0.022)$, 
Table 2. Frequency of dietary supplement consumption according to the supplement type.

\begin{tabular}{lc}
\hline Food supplement & $\begin{array}{c}\text { Number } \\
\text { of users (\%) }\end{array}$ \\
\hline Vitamin D & $36(53.7)$ \\
Vitamin B12 & $26(38.8)$ \\
Calcium & $17(25.4)$ \\
Iron & $6(9)$ \\
Omega 3 & $6(9)$ \\
Vitamin B6 & $6(9)$ \\
Multivitamin & $6(9)$ \\
Folic acid & $5(7.5)$ \\
Laxatives (mainly Senna based) & $5(7.5)$ \\
Vitamin C & $4(6)$ \\
Megagluflex & $4(6)$ \\
(Chondroitin + Glucosamine) & $4(6)$ \\
Probiotics & \\
\hline
\end{tabular}

female gender $(\mathrm{OR}=2.94, \mathrm{p}=0.014)$ and routine physical activity $(\mathrm{OR}=3.15, \mathrm{p}=0.007)$. Diabetes mellitus $(\mathrm{OR}=2.68, \mathrm{p}=0.020)$, hematological diseases $(\mathrm{OR}=13.29, \mathrm{p}=0.022)$, and the use of anti-diabetic medications $(\mathrm{OR}=4.28, \mathrm{p}=0.001)$ were independently associated with dietary supplement intake (Table 4).

A comparison of the demographic characteristics, habits, medical history and chronic medications intake of the dietary supplement consuming patients according to the hospitalization ward (Internal Medicine vs. Cardiology) is presented in Table 5. Patients admitted to the Internal Medicine Wards were not significantly older (69.9 years vs. 66.5 years, $\mathrm{p}=0.18$ ), had more chronic IHD ( $66.7 \%$ vs. $35.1 \%, \mathrm{p}=0.01)$, diabetes mellitus ( $70.0 \%$ vs. $35.1 \%, \mathrm{p}=0.005)$, pulmonary diseases ( $23.3 \%$ vs. $2.7 \%, \mathrm{p}=0.018)$ and gastrointestinal diseases (33.3\% vs. $10.8 \%, \mathrm{p}=0.024)$ than those admitted to the Cardiology Division. Also, those admitted to the Internal Medicine Wards received chronic treatment with calcium channel blockers, alpha-blockers, angiotensin converting enzyme inhibitors/angiotensin receptor blockers, statins, and anti-diabetes medication at a greater rate than those admitted to the Cardiology Wards (53.3\% vs. $27.0 \%, \mathrm{p}=0.028 ; 40.0 \%$ vs. $8.1 \%, \mathrm{p}=0.002 ; 83.3 \%$ vs. $54.1 \%, p=0.011 ; 90.0 \%$ vs. $62.2 \%, p=0.009$ and $56.7 \%$ vs. $29.47 \%, \mathrm{p}=0.026$, respectively). The admission diagnosis of acute IHD was the only variant found to be statistically significant in those admitted to the Cardiology Wards compared to Internal Medicine Wards $(43.2 \%$ vs. $16.7 \%, \mathrm{p}=0.020)$.
Consumption of dietary supplements in patients hospitalized in Internal Medicine Wards was associated with age $(\mathrm{OR}=1.08, \mathrm{p}=0.024)$ and the use of anti-diabetic medication $(\mathrm{OR}=10.76$, $\mathrm{p}=0.005)$ (Table 6). Age $(\mathrm{OR}=1.05, \mathrm{p}=0.036)$, female gender $(\mathrm{OR}=2.74, \mathrm{p}=0.044)$, admission diagnosis other than acute IHD $(\mathrm{OR}=3.45, \mathrm{p}=0.010)$, and the use of levothyroxine $(\mathrm{OR}=16.28$, $\mathrm{p}=0.024$ ) were found to be associated with dietary supplement consumption in patients hospitalizes in the Cardiology Division. Sixteen potential moderate drug-dietary supplement interactions were found (Table 7 ). No severe potential interaction was noted.

\section{Discussion}

Our study shows that dietary supplements were consumed by $45 \%$ of cardiac patients and half of them suffered from a chronic IHD and/or diabetes. Most patients consuming dietary supplements were Jewish, born in Israel or Eastern Europe, married, with an education level of at least high school, earning average or above average salaries, physically active, non-smokers and did not consume alcohol or drugs routinely. Patients consuming dietary supplements admitted to the Internal Medicine Wards were found to be older with a higher body mass index than those admitted to the Cardiology Division. This may be explained by the advanced ages and multiple chronic diseases and complications of patients admitted to Internal Medicine Wards. These data were supported by Goldstein et al. [8] who reported that females, married individuals, those earning an above average salary with a higher level of education and non-smokers, consumed more dietary supplements. Moreover, the profile of dietary supplement consumption in the United States was found to be: female sex $(52 \%)$, age of 50 years or older $(35 \%)$, higher level of education (49\%), and an average income (45\%; $\$ 20,000-\$ 49,000 /$ year) with a rising tendency at the higher income levels $[9,10]$. An Australian meta-analysis performed in 2010 by Bin et al. [11] reviewed 20 studies conducted worldwide. The study revealed that $36 \%$ of patients with cardiac diseases consume dietary supplements. It was also found that those consuming dietary supplements tended to take more than 1 supplement per day. Two of the reviewed studies demonstrated the use of 2 dietary supplements on average [12, 13] while another observed the use of 3 supplements per patient [14]. The most frequent dietary supplements consumed were multivitamins and 
Table 3. Demographic characteristics, habits and medical history of patients consuming food supplement. Univariate analysis: comparison consumers and non-consumers.

\begin{tabular}{|c|c|c|c|}
\hline Characteristic & $\begin{array}{l}\text { Consumers }(n=67) \\
\text { Mean } \pm \text { SD or } n(\%)\end{array}$ & $\begin{array}{c}\text { Non consumers }(n=82) \\
\text { Mean } \pm \text { SD or } n(\%)\end{array}$ & $\mathbf{P}$ \\
\hline Body mass index & $29.51 \pm 4.38$ & $29.55 \pm 5.28$ & 0.956 \\
\hline Age & $68.03 \pm 10.42$ & $60.99 \pm 10.76$ & $<0.001^{*}$ \\
\hline Hospitalization Ward: & & & $0.005^{*}$ \\
\hline Internal Medicine & $30(44.8)$ & $19(23.2)$ & \\
\hline Cardiology & $37(55.2)$ & $63(76.8)$ & \\
\hline Gender — female & $33(49.3)$ & $20(24.4)$ & $0.002^{*}$ \\
\hline Family status: & & & 0.064 \\
\hline Married & $44(65.7)$ & $66(80.5)$ & \\
\hline Divorced & $16(23.9)$ & $9(11)$ & \\
\hline Widowed & $7(10.4)$ & $5(6.1)$ & \\
\hline Single & $0(0.0)$ & $2(2.4)$ & \\
\hline Ethnic origin: & & & 0.089 \\
\hline Jewish & $63(94.0)$ & $70(85.4)$ & \\
\hline Arabic & $4(6.0)$ & $12(14.6)$ & \\
\hline Education: & & & 0.365 \\
\hline No education & $3(4.5)$ & $6(7.3)$ & \\
\hline Elementary school & $8(11.9)$ & $16(19.5)$ & \\
\hline High school & $30(44.8)$ & $27(32.9)$ & \\
\hline Academic & $26(38.8)$ & $33(40.2)$ & \\
\hline Salary: & & & 0.619 \\
\hline Significantly below average & $3(4.5)$ & $2(2.4)$ & \\
\hline Below average & $7(10.4)$ & $13(15.9)$ & \\
\hline Average & $9(13.4)$ & $15(18.3)$ & \\
\hline Above average & $18(26.9)$ & $23(28.0)$ & \\
\hline Significantly above average & $30(44.8)$ & $29(35.4)$ & \\
\hline Birth place: & & & 0.319 \\
\hline Israel & $20(29.9)$ & $36(43.9)$ & \\
\hline Eastern Europe & $27(40.3)$ & $26(31.7)$ & \\
\hline Northern Africa & $9(13.4)$ & $11(13.4)$ & \\
\hline Other & $11(16.4)$ & $9(11.0)$ & \\
\hline Routine physical activity & $33(49.3)$ & $25(30.5)$ & $0.019 *$ \\
\hline Smoking: & & & $0.023^{*}$ \\
\hline Non smoker & $36(53.7)$ & $29(35.4)$ & \\
\hline Current smoker & $9(13.4)$ & $25(30.5)$ & \\
\hline Past smoker & $22(32.8)$ & $28(34.1)$ & \\
\hline Admission diagnosis of acute IHD & $21(31.3)$ & $48(58.5)$ & $0.001^{*}$ \\
\hline IHD & $33(49.3)$ & $40(48.8)$ & 0.954 \\
\hline Congestive heart failure & $14(20.9)$ & $19(57.6)$ & 0.739 \\
\hline Valvular heart disease & $4(6.0)$ & $8(9.8)$ & 0.398 \\
\hline Cardiac arrhythmia & $21(31.3)$ & $17(20.7)$ & 0.139 \\
\hline Diabetes mellitus & $34(50.7)$ & $21(25.6)$ & $0.002 *$ \\
\hline
\end{tabular}

* $p$ value represents the statistically significant correlation compared to the patients not consuming dietary supplements; IHD — ischemic heart disease; SD — standard deviation 
Table 4. Demographic characteristics, habits and medical history of patients consuming food supplements. Multivariate analysis and backward regression analysis of age, gender, physical activity that were found to correlate significantly with I - medical condition and II - medications.

\begin{tabular}{|c|c|c|c|}
\hline Variant & Odds ratio & $95 \% \mathrm{Cl}$ & $\mathbf{P}^{*}$ \\
\hline \multicolumn{4}{|l|}{ I } \\
\hline Age [years] & 1.05 & $1.01-1.09$ & $0.022 *$ \\
\hline Female gender & 2.94 & $1.25-6.67$ & $0.014 *$ \\
\hline Routine physical activity & 3.15 & $1.36-7.28$ & $0.007 *$ \\
\hline Admission diagnosis other than acute ischemic heart disease & 2.04 & $0.91-4.76$ & 0.085 \\
\hline Diabetes mellitus & 2.68 & $1.17-6.14$ & $0.020 *$ \\
\hline Gastrointestinal disease & 3.58 & $0.95-13.54$ & 0.060 \\
\hline Hematological disease & 13.29 & $1.46-121.50$ & $0.022 *$ \\
\hline \multicolumn{4}{|l|}{ II } \\
\hline Age [years] & 1.06 & $1.02-1.10$ & $0.003^{*}$ \\
\hline Female gender & 3.13 & $1.33-7.14$ & $0.009 *$ \\
\hline Routine physical activity & 3.07 & $1.38-6.81$ & $0.006^{*}$ \\
\hline Use of anti-diabetic medication & 4.28 & $1.75-10.45$ & $0.001 *$ \\
\hline Levothyroxin use & 8.27 & $0.89-76.8$ & 0.063 \\
\hline
\end{tabular}

${ }^{*} \mathrm{p}$ value represents the statistically significant correlation compared to the patients not consuming dietary supplements; $\mathrm{Cl}$ — confidence interval

minerals. The data from our study revealed that most of the patients consumed 1 or 2 dietary supplements per day. Most of the patients consumed vitamin $\mathrm{D}$, vitamin $\mathrm{B} 12$ or calcium.

Several moderate interactions were identified in our study. Interactions between vitamin $\mathrm{D}$ and conventional medications were found: vitamin D induces cytochrome P450 3A4 enzyme activity, which metabolizes atorvastatin in the gut. Thus, a combination of vitamin $\mathrm{D}$ and atorvastatin could reduce the bioavailability of the drug. Schwartz et al. [15] examined 16 patients with and without supplemented vitamin $\mathrm{D}$ and demonstrated that those who consumed vitamin $\mathrm{D}$ products significantly reduced the levels of atorvastatin active metabolites by $55 \%$, while the levels of different components of cholesterol did not change. High doses of vitamin D could cause hypercalcemia, which might increase the risk of fatal cardiac arrhythmias when administered with digoxin, thiazide diuretics or verapamil [15]. In this study, 26 (72.2\% of vitamin D consumers) consumed vitamin $\mathrm{D}$ with statins.

Calcium supplements taken with levothyroxine were found to reduce the efficacy of the medication [16]. In vitro studies showed that levothyroxine adsorbs to calcium carbonate at low $\mathrm{pH}$ levels (as in the stomach) thereby deregulating its efficacy [17]. In this study, 3 patients (17.6\% of calcium consumers) consumed calcium with levo- thyroxine. We do not have information regarding the timing of consumption.

The effects of the interaction of fish oil (which includes omega 3 ) and warfarin have been extensively studied, yet the data are contradictory. In 2 different studies, fish oil consumption had no effect on bleeding time. However, Buckley et al. [18] presented a case report in which omega 3 significantly increased bleeding time in patients who consumed warfarin when doubling the fish oil intake. It was suggested that the antithrombotic activity mechanism applied to omega 3 could contribute to the increased bleeding time observed. In the present study, 2 patients (33.3\% of omega 3 consumers) consumed omega 3 with warfarin.

It is of note that in our group of cardiac patients (the whole study population), omega 3 was consumed by $9 \%$ of the patients and no bleeding tendency was observed.

In addition, aspirin (consumed by 21 patients) and $\mathrm{H} 2$ blockers (consumed by 1 patient) were found to reduce the absorption of vitamin B12 from the intestine $(80.7 \%$ and $3.8 \%$, respectively, of vitamin B12 consuming patients) [16]. Moreover, aspirin reduces the absorption of vitamin $\mathrm{C}$ by one third, yet the level aspirin itself is not affected by vitamin $\mathrm{C}$ (aspirin was consumed by 3 patients; 75\% of vitamin C consumers) [16]. 
Table 5. Demographic characteristics, habits, medical history and conventional medication intake of patients consuming food supplement, admitted to the Internal Medicine Wards vs. Cardiology Division — univariate analysis.

\begin{tabular}{|c|c|c|c|}
\hline Characteristic & $\begin{array}{l}\text { Internal Medicine Ward }(n=30) \\
\text { Mean } \pm \text { SD or } n(\%)\end{array}$ & $\begin{array}{c}\text { Cardiology Division }(n=37) \\
\text { Mean } \pm \text { SD or } n(\%)\end{array}$ & $\mathbf{P}^{*}$ \\
\hline Average BMI & $30.9 \pm 4.8$ & $28.3 \pm 3.6$ & $0.013^{*}$ \\
\hline Average age [years] & $69.9 \pm 10.2$ & $66.5 \pm 10.4$ & 0.180 \\
\hline Gender: & & & 0.912 \\
\hline Male & $15(50.0)$ & $19(51.4)$ & \\
\hline Female & $15(50.0)$ & $18(48.6)$ & \\
\hline Family status: & & & 0.240 \\
\hline Single & $0(0.0)$ & $0(0.0)$ & \\
\hline Married & $17(56.7)$ & $27(73.0)$ & \\
\hline Divorced & $8(26.7)$ & $8(21.6)$ & \\
\hline Widowed & $5(16.7)$ & $2(5.4)$ & \\
\hline Ethnic origin: & & & 0.318 \\
\hline Jewish & $27(90.0)$ & $36(97.3)$ & \\
\hline Arabic & $3(10.0)$ & $1(2.7)$ & \\
\hline Education: & & & 0.199 \\
\hline No education & $2(6.7)$ & $1(2.7)$ & \\
\hline Elementary school & $6(20.0)$ & $2(5.4)$ & \\
\hline High school & $13(43.3)$ & $17(45.9)$ & \\
\hline Academic & $9(30.0)$ & $17(45.9)$ & \\
\hline Salary: & & & 0.289 \\
\hline Significantly below average & $1(3.3)$ & $2(5.4)$ & \\
\hline Below average & $1(3.3)$ & $6(16.2)$ & \\
\hline Average & $3(10.0)$ & $6(16.2)$ & \\
\hline Above average & $8(26.7)$ & $10(27.0)$ & \\
\hline Significantly above average & $17(56.7)$ & $13(35.1)$ & \\
\hline Birth place: & & & 0.434 \\
\hline Israel & $6(20.0)$ & $14(37.8)$ & \\
\hline Eastern Europe & $14(46.7)$ & $13(35.1)$ & \\
\hline Northern Africa & $5(16.7)$ & $4(10.8)$ & \\
\hline Other & $5(16.7)$ & $6(16.2)$ & \\
\hline Routine physical activity & $14(46.7)$ & $19(51.4)$ & 0.703 \\
\hline Smoking: & & & 0.557 \\
\hline No & $14(46.7)$ & $22(59.5)$ & \\
\hline Yes & $5(16.7)$ & $4(10.8)$ & \\
\hline In the past & $11(36.7)$ & $11(29.7)$ & \\
\hline Admission diagnosis of acute IHD & $5(16.7)$ & $16(43.2)$ & $0.020 *$ \\
\hline Ischemic heart disease & $20(66.7)$ & $13(35.1)$ & $0.010 *$ \\
\hline Congestive heart failure & $8(26.7)$ & $6(16.2)$ & 0.295 \\
\hline Valvular heart disease & $1(3.3)$ & $3(8.1)$ & 0.622 \\
\hline Cardiac arrhythmia & $11(36.7)$ & $10(27.0)$ & 0.398 \\
\hline Diabetes mellitus & $21(70.0)$ & $13(35.1)$ & $0.005^{*}$ \\
\hline Pulmonary disease & $7(23.3)$ & $1(2.7)$ & $0.018 *$ \\
\hline Gastrointestinal disease & $10(33.3)$ & $4(10.8)$ & $0.024^{*}$ \\
\hline Chronic renal failure & $6(20.0)$ & $4(10.8)$ & 0.324 \\
\hline Hematologic disease & $7(23.3)$ & $2(5.4)$ & 0.067 \\
\hline Aspirin intake & $24(80.0)$ & $22(59.5)$ & 0.072 \\
\hline Calcium channel blocker intake & $16(53.3)$ & $10(27.0)$ & $0.028 *$ \\
\hline ACE/ARB intake & $25(83.3)$ & $20(54.1)$ & $0.011^{*}$ \\
\hline Alpha-blocker intake & $12(40.0)$ & $3(8.1)$ & $0.002 *$ \\
\hline Statins & $27(90.0)$ & $23(62.2)$ & $0.009 *$ \\
\hline Anti-diabetic medications intake & $17(56.7)$ & $11(29.7)$ & $0.026 *$ \\
\hline Levothyroxin & $3(10.0)$ & $5(13.5)$ & 0.722 \\
\hline
\end{tabular}

${ }^{*} p$ value represents the statistically significant correlation comparing the dietary consumers in the Internal Wards with those in the Cardiology Division; ACE — angiotensin converting enzyme; ARB — angiotensin receptor blocker; BMI — body mass index; IHD — ischemic heart disease 
Table 6. Demographic characteristics, habits, medical history and conventional medication intake of patients consuming food supplement, admitted to the Internal Medicine Wards vs. Cardiology Division - multivariate analysis and backward regression analysis of factors having significant correlation with “Dietary Supplement” intake: I - Internal Medicine Ward, II - Cardiology Division.

\begin{tabular}{lccc}
\hline Variant & Odds ratio & $95 \%$ Cl & $\mathbf{P}^{*}$ \\
\hline I & & & \\
Age [years] & 1.08 & $1.01-1.15$ & $0.024^{*}$ \\
Female gender & 2.76 & $0.65-11.77$ & 0.170 \\
Use of anti-diabetic medication & 10.76 & $2.07-55.83$ & $0.005^{*}$ \\
II & & $1.00-1.10$ & $0.036^{*}$ \\
Age [years] & 1.05 & $1.03-7.31$ & $0.044^{*}$ \\
Female gender & 2.74 & $0.11-0.74$ & $0.010^{*}$ \\
Admission diagnosis other than acute ischemic heart disease & 3.45 & $1.43-184.85$ & $0.024^{*}$ \\
Use of levothyroxin & 16.28 & 1.85 \\
\hline
\end{tabular}

${ }^{*} p$ value representing the statistically significant correlation comparing the dietary consumers in the Internal Wards with those in the Cardiology Division; $\mathrm{Cl}$ - confidence interval

Table 7. Dietary supplement-drug interactions.

\begin{tabular}{|c|c|c|c|}
\hline Dietary supplement & Interacting drug & Type of interaction & Details \\
\hline Vitamin D & Atorvastatin & Pharmacokinetic & $\begin{array}{l}\text { Vitamin D induces cytochrome P450 3A4 } \\
\text { enzyme activity which can reduce } \\
\text { atorvastatins' bioavailability }\end{array}$ \\
\hline Vitamin D & Digoxin & Pharmacodynamic & $\begin{array}{l}\text { High doses of vitamin D can cause } \\
\text { hypercalcemia and fatal cardiac } \\
\text { arrhythmias with digoxin }\end{array}$ \\
\hline Vitamin D & Thiazide & Pharmacodynamic & $\begin{array}{l}\text { Thiazides decrease urinary calcium } \\
\text { excretion, which could lead to } \\
\text { hypercalcemia if vitamin D supplements } \\
\text { are taken concurrently }\end{array}$ \\
\hline Vitamin D & Verapamil & Pharmacodynamic & $\begin{array}{l}\text { High doses of vitamin D can reduce } \\
\text { the effectiveness of verapamil in atrial } \\
\text { fibrillation }\end{array}$ \\
\hline Calcium & Levothyroxin & Pharmacokinetic & $\begin{array}{l}\text { Levothyroxine binds to calcium } \\
\text { carbonate at low pH levels (as in the } \\
\text { stomach) thereby lowering its efficacy }\end{array}$ \\
\hline Omega 3 & Warfarin & Pharnakodynamic & $\begin{array}{l}\text { Omega } 3 \text { fatty acids are considered to } \\
\text { have some antiplatelet activity, and may } \\
\text { prolong the bleeding time. Also, may } \\
\text { reduce levels of some coagulation } \\
\text { factors. Used with warfarin may } \\
\text { increase bleeding risk }\end{array}$ \\
\hline Vitamin B12 & Aspirin & Pharmacokinetic & \multirow{2}{*}{$\begin{array}{l}\text { Aspirin and } \mathrm{H} 2 \text { blockers reduce the } \\
\text { absorption of vitamin } \mathrm{B} 12 \text { from } \\
\text { the intestine }\end{array}$} \\
\hline Vitamin B12 & H2 blockers & Pharmacokinetic & \\
\hline Vitamin C & Aspirin & Pharmacokinetic & $\begin{array}{l}\text { Aspirin reduces the absorption of } \\
\text { vitamin } C \text { by one third }\end{array}$ \\
\hline
\end{tabular}

\section{Limitations of the study}

The study was conducted in one medical center with its own hospitalization admittance criteria to the different wards. Not all admitted patients were included in the study. Some of the patients could not participate in the study due to their health status and therefore the research population does not represent a complete picture of the hospitalized 
patient population. This could affect the incidence results of dietary supplement use and possibly also of interactions between them and the conventional medications that have possibly been overlooked.

The patients examined were hospitalized in wards with an internal profile nature (Internal Departments and the Cardiology Division). The results might possibly have been different, to a certain degree, had we included patients hospitalized in the surgical units.

\section{Conclusions}

Most patients suffering from a heart disease consume 1 or 2 dietary supplements per day. More patients admitted to the Internal Medicine Wards consumed dietary supplements than those admitted to the Cardiology Division. Physical activity, hematological disease history, age, female gender and the use of anti-diabetic medications were found to be significantly associated with dietary supplement consumption.

Although potential life-threatening interactions were not found in our study, there is a need to increase awareness and knowledge among medical staff regarding the intake of dietary supplements. Moreover, further studies focusing on the relationship between dietary supplement intake and medications for various chronic diseases are needed.

\section{Conflict of interest: None declared}

\section{References}

1. Gardiner P, Phillips R, Shaughnessy AF. Herbal and dietary supplement-drug interactions in patients with chronic illnesses. Am Fam Physician, 2008; 77: 73-78.

2. http://nccam.nih.gov/health/supplements.
3. Gardiner P, Graham RE, Legedza AT, Eisenberg DM, Phillips RS. Factors associated with dietary supplement use among prescription medication users. Arch Intern Med, 2006; 166: 1968-1974.

4. Psota TL, Gebauer SK, Kris-Etherton P. Dietary omega-3 fatty acid intake and cardiovascular risk. Am J Cardiol, 2006; 98: 3i-18i.

5. Kris-Etherton PM, Harris WS, Appel LJ. Fish consumption, fish oil, omega-3 fatty acids, and cardiovascular disease. American Heart Association. Nutrition Committee Circulation, 2002; 106: 2747-2757.

6. Smith SC Jr, Allen J, Blair SN et al. AHA/ACC guidelines for secondary prevention for patients with coronary and other atherosclerotic vascular disease: 2006 update: endorsed by the National Heart, Lung, and Blood Institute. Circulation, 2006; 113: 2363-2372.

7. Priori SG, Aliot E, Blomstrom-Lundqvist C et al. European Society of Cardiology. Update of the guidelines on sudden cardiac death of the European Society of Cardiology. Eur Heart J, 2003; 24: 13-15.

8. Goldstein LH, Elias M, Ron-Avraham G et al. Consumption of herbal remedies and dietary supplements amongst patients hospitalized in medical wards. Br J Clin Pharmacol, 2007; 64: 373-380.

9. Eisenberg DM, Davis RB, Ettner SL, Appel S et al. Trends in alternative medicine use in the United States, 1990-1997: Results of a follow-up national survey. JAMA, 1998; 280: 1569-1575.

10. Eisenberg DM, Kessler RC, Foster C, Norlock FE, Calkins DR, Delbanco TL. Unconventional Medicine in the United States: Prevalence, costs, and patterns of use. N Engl J Med, 1993; 328: 246-252.

11. Bin YS, Kiat H. Prevalence of dietary supplement use in patients with proven or suspected cardiovascular disease. Evid Based Complement Alternat Med, 2011; 632829.

12. Chagan L, Bernstein D, Cheng JWM et al. Use of biological based therapy in patients with cardiovascular diseases in a university-hospital in New York City. BMC Complementary and Alternative Med, 2005; 3: 4.

13. Yilmaz MB, Yontar OC, Turgut OO et al. Herbals in cardiovascular practice: Are physicians neglecting anything? Int J Cardiol, 2007; 122: 48-51.

14. Stys T, Stys A, Kelly P, Lawson W. Trends in use of herbal and nutritional supplements in cardiovascular patients. Clin Cardiol, 2004; 27: 87-90.

15. Schwartz JB. Effects of vitamin D supplementation in atorvastatin-treated patients: A new drug interaction with an unexpected consequence. Clin Pharmacol Ther, 2009; 85: 198-203.

16. Baxter K ed. Stockley's drug interactions. $8^{\text {th }}$ Ed. Pharmaceutical Press, London 2008.

17. Schneyer CR. Calcium carbonate and reduction of levothyroxine efficacy. JAMA, 1998; 279: 750.

18. Buckley MS, Goff AD, Knapp WE. Fish oil interaction with warfarin. Ann Pharmacother, 2004; 38: 50-52. 